\title{
Preoperative Body Mass Index and Postoperative Complications After Pelvic Exenteration in Recurrent or Locally Advanced Rectal Cancer Patients
}

\author{
Moo-Jun Baek \\ Department of Surgery, Soonchunhyang University Cheonan Hospital, Soonchunhyang University College of Medicine, Cheonan, Korea
}

\section{See Article on Page 83-87}

Generally, much work has been done on the relationship between postoperative complications and malnutrition, and malnutrition is well known to contribute greatly to postoperative complications [1-3]. Radical surgeries, like pelvic exenteration, as a treatment method for recurrent or locally advanced rectal cancer can trigger more complications and cause more postoperative mortalities than common rectal cancer surgeries, like a low anterior resection. Thus, when performing such radical surgeries, the patients' systemic state will be an extremely important factor in determining the outcome. In this respect, if we can easily evaluate a patient's state before surgery based on his or her body mass index (BMI), that would be a good reference in considering surgical methods [4].

There has not been yet much work on the relationship between patients' BMI or nutritional states and morbidities or mortalities after pelvic exoneration surgery. This may be because prospective work is difficult and the number of such patients is not great. Thus, this study seems to have great significance. Because pelvic exenteration surgery for recurrent or locally advanced rectal cancer is difficult to perform, it has not been widely performed in many institutions. As mentioned by the authors, the value of this study seems big regardless of its limitations. Prospective studies on more cases in the future will give a more accurate and precise answer to the question addressed in this study.

Correspondence to: Moo-Jun Baek, M.D.

Department of Surgery, Soonchunhyang University Cheonan Hospital, Soonchunhyang University College of Medicine, 31 Suncheonhyang 6-gil, Dongnam-gu, Cheonan 330-930, Korea

Tel: +82-41-570-3633, Fax: +82-41-571-0129

E-mail: ssurge@sch.ac.kr

(C) 2014 The Korean Society of Coloproctology

This is an open-access article distributed under the terms of the Creative Commons Attribution NonCommercial License (http://creativecommons.org/licenses/by-nc/3.0) which permits unrestricted noncommercial use, distribution, and reproduction in any medium, provided the original work is properly cited.

\section{REFERENCES}

1. Kuppinger D, Hartl WH, Bertok M, Hoffmann JM, Cederbaum J, Bender A, et al. Nutritional screening for risk prediction in patients scheduled for extra-abdominal surgery. Nutrition 2013;29: 399-404.

2. Huhmann MB, August DA. Perioperative nutrition support in cancer patients. Nutr Clin Pract 2012;27:586-92.

3. Kim MS, Kim HK, Kim DY, Ju JK. The influence of nutritional assessment on the outcome of ostomy takedown. J Korean Soc Coloproctol 2012;28:145-51.

4. Beaton J, Carey S, Solomon MJ, Tan KK, Young J. Preoperative body mass index, 30-day postoperative morbidity, length of stay and quality of life in patients undergoing pelvic exenteration surgery for recurrent and locally-advanced rectal cancer. Ann Coloproctol 2014;30:83-7. 